\title{
Vesicle self-assembly of amphiphilic siderophores produced by bacterial isolates from Soap Lake, Washington
}

\author{
Author: Luis O'mar Serrano Figueroa, Betsey Pitts, \\ Masaki Uchida, \& Abigail M. Richards
}

NOTICE: This is a postprint of an article that originally appeared in Canadian Journal of Chemistry on January 2016. DOI: https://doi.org/10.1139/cjc-2015-0173

Figueroa LO, Pitts B, Uchida M, Richards AM, "Vesicle self-assembly of amphiphilic siderophores produced by bacterial isolates from Soap Lake, Washington," Can. J. Chem. 2016 94(1):35-43. 


\title{
Vesicle self-assembly of amphiphilic siderophores produced by bacterial isolates from Soap Lake, Washington
}

\author{
Luis O'mar Serrano Figueroa, Betsey Pitts, Masaki Uchida, and Abigail M. Richards
}

\begin{abstract}
L.O. Serrano Figueroa. Department of Microbiology and Immunology, Montana State University, Bozeman, MT 59717, USA; Center for Biofilm Engineering, Montana State University, Bozeman, MT 59717, USA.

B. Pitts. Center for Biofilm Engineering, Montana State University, Bozeman, MT 59717, USA.

M. Uchida. Department of Chemistry and Biochemistry, Montana State University, Bozeman, MT 59717, USA.

A.M. Richards. Center for Biofilm Engineering, Montana State University, Bozeman, MT 59717, USA; Department of Chemical and Biological Engineering, Montana State University, Bozeman, MT 59717, USA.
\end{abstract}

\begin{abstract}
Soap Lake, located in Washington State, is a meromictic soda lake that was the subject of a prior National Science Foundation funded Microbial Observatory. Several organisms inhabiting this lake have been identified as producers of sidero-phores that are unique in structure. Two isolates found to be of the species Halomonas, SL01 and SL28, were found to produce suites of amphiphilic siderophores consisting of a peptidic head-group, which binds iron appended to fatty acid moieties of various lengths. The ability for siderophores to self-assemble into vesicles was determined for three suites of amphiphilic siderophores of unique structure (two from SL01 and one from SL28). These siderophores resemble the amphiphilic aquachelin siderophores produced by Halomonas aquamarina strain DS40M3, a marine bacterium. Vesicle self-assembly studies were per-formed by dynamic light scattering and epifluorescence microscopy. The addition of ferric iron $\left(\mathrm{Fe}^{3+}\right)$ at different equivalents, where an equivalence of iron is defined as equal to the molarity of the siderophore, demonstrated vesicle formation. This was suggested by both dynamic light scattering and epifluorescence microscopy. Bacteria thriving under saline and alkaline condi-tions are capable of producing unique siderophores that self-assemble in micelles and vesicles due to ferric iron chelation.
\end{abstract}

Key words: amphiphilic siderophores, vesicles, self-assembly, iron, critical micelle concentration.

Résumé : Le lac Soap, situé dans l'État de Washington, est un lac méromictique alcalin ayant déjà fait partie du programme d'un observatoire des microorganismes financé par la National Science Foundation. De nombreux microorganismes vivant dans ce lac ont été répertoriés comme étant des producteurs de sidérophores uniques de par leur structure. Nous avons identifié dans deux isolats l'espèce Halomonas, et observé que les structures SL01 et SL28 produisaient des séries de sidérophores amphiphiles constitués d'une tête peptidique qui se lie au fer, accrochée à des groupements acides gras de différentes longueurs. Nous avons déterminé la capacité des sidérophores à s'autoassembler en vésicules pour trois suites de sidérophores amphiphiles de structure unique (deux de structure SL01 et une de structure SL28). Ces sidérophores ressemblent aux sidérophores amphiphiles de type aquacheline prođuits par la souche DS40M3 d'Halomonas aquamarina, une bactérie marine. Nous avons effectué des études d'autoassemblage de vésicules par diffusion dynamique de la lumière et microscopie à épiffuorescence. L'addition d'ions ferriques $\left(\mathrm{Fe}^{3+}\right) \mathrm{a}$ différentes proportions équivalentes, où un équivalent de fer est défini comme égal à la molarité du sidérophore, a provoqué la formation de vésicules. Ces observations sont corroborées tant par la diffusion dynamique de la lumière que par la microscopie à épifluorescence. Les bactéries qui survivent en conditions salines et alcalines sont capables de produire des sidérophores particuliers qui s'autoassemblent en micelles et en vésicules grâce au phénomène de chélation des ions ferriques. [Traduit par la Rédaction]

Mots-clés : sidérophores amphiphiles, vésicules, autoassemblage, fer, concentration micellaire critique.

\section{Introduction}

Iron is an important mineral for nearly all living organisms, and bacteria have developed siderophores for its uptake. Siderophores are low molecular weight compounds that specifically coordinate ferric iron $\left(\mathrm{Fe}^{3+}\right)$. In addition to siderophores, metal chelation can occur through different molecules, like cardiolipins and phosphati-dylserine, which bind ferric iron and manganese. ${ }^{1}$ While specific for the coordination of iron, some siderophores can form stable com-plexes with other metal ions. Examples include the chelation of uranium(VI) by deferrioxamine B and pyochelins. 2,3 Other researchers have demonstrated neptunium(V) and boron chelation 4,5 Some sid-erophores are amphiphilic, which means the molecule has both hy-drophilic and hydrophobic properties. Amphiphilic siderophores form micelles above a threshold concentration and are shown to self-assemble into vesicles when excess ferric iron is chelated. ${ }^{6-8}$ The self-assembly in amphiphilic siderophores was first described by Martinez and co-workers (2000).8 Those physicochemical proper-ties confer upon siderophores the potential to form micelles in their deferrated form, when over their critical micelle concentra-tion (cmc), which in marinobactins and aquachelins is about 25-150 mol/L. Trends of higher cmc are expected when siderophores are ferrated.

Micelle-to-vesicle transitions for marinobactin E, yielding vesicles of approximately 140-180 $\mathrm{nm}$ in size, were shown via dynamic light scattering (DLS).8 Because the diameter of micelles formed by sidero-phores is near the limit of detection of DLS, other methods are typically used to determine their size. For example, small-angle neutron scattering (SANS) in combination with DLS has been used to account for micelle formation. 6 Siderophores are shown to form micelles when coordinating iron and when in the iron-free form. In the 
Fig. 1. Halochelins and sodachelins selected for micelle-to-vesicle studies. (A and B) Halochelin family: (C) sodachelin family. Circled fatty acids indicate amphiphilic siderophores selected in this study.

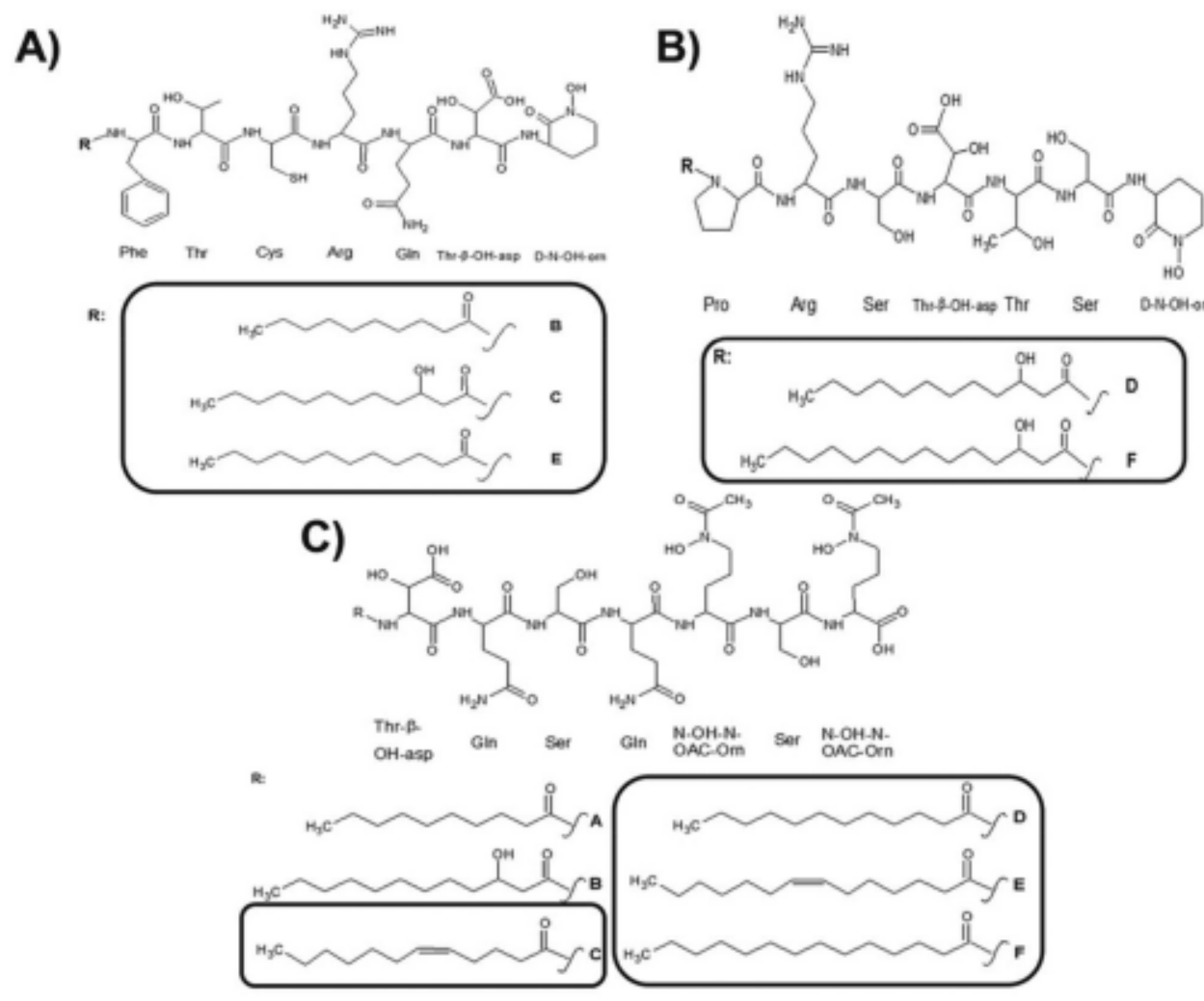

iron-free state, siderophore micelles are approximately $4 \mathrm{~nm}$ in diameter. With the coordination of ferric iron, the micelles decrease in size to approximately $3 \mathrm{~nm}$. The decrease in size of micelles is due to a conformational change of the iron-binding peptide headgroup. Further addition of ferric iron results in particles of increased diameter, up to $200 \mathrm{~nm}$. This structural reassembly from micelles into larger vesicle-like structures is due to the realignment of fatty acid moieties when siderophores coordinate excess iron via the free carboxylate ( $\mathrm{COO}-$ ) groups located at the C-terminus. Vesicle self-assembly also occurs in amphiphilic siderophores due to metals other than iron. ${ }^{7} \mathrm{Zinc}$ (II) and cadmium(II) interact in the same fashion with the amphiphiles and micelle-to-vesicle transitions are observed as well as multilamellar vesicle formation in previous studies by the same group of researchers. ${ }^{6}$ At higher $\mathrm{Zn}^{+2}$ equivalents, zinc-induced micelle-tovesicle transition produced three types of vesicles varying in bilayers numbers (6-8). With SANS, it was possible to determine the interbilayer and bilayer thicknesses. In another study. X-ray diffraction and X-ray absorption spectroscopy were used to determine the distance between bilayers and the mode of coordination. respectively. ${ }^{9}$ In this case, zinc(II) and cadmium(II) were added to ferri-marinobactin E previously formed in micelles. Amphiphilic siderophore free-carboxylate groups caused divalent cation chelation and micelle-to-vesicle transition occurred.

Cryogenic transmission electron microscopy (cryo-TEM) is often used to confirm vesicle formation. This qualitative method has provided researchers results similar to those obtained with previous quantitative methods discussed above. ${ }^{-s} \mathrm{~A}$ study used cryo-TEM on synthetic amphiphilic siderophores, sulfonated monocatechols, and their self-assembly properties. ${ }^{10}$ Researchers also used UV spectra. $\mathrm{pK}_{\mathrm{a}}$, complexation constants, and surface tension for physicochemical characterization properties of these molecules with iron chelation. Vesicles can also be identified using confocal microscopy and staining with fluorophores. ${ }^{11}$ In this particular study. researchers developed a method to observe cellular vesicles produced by Cryptococcus neoformans. Other studies focused onvesicles derived from cells and they employed similar microscopic techniques. ${ }^{12,13}$ One study used lipids to form giant vesicles stained with rhodamine and fluorescein, while another utilized BODIPY lipids as staining agents of the actin-containing dimyristoylphosphatidylcholine vesicles. ${ }^{14,15}$ Fluoresence microscopy was utilized to observe and characterize the morphology of the structures.

Here, we present results of particle size analysis of selected sodachelins and halochelins produced by strains Halomonas sp. SL28 and SL01(Fig. 1), respectively. at different ferric iron equivalents. The micelle-to-vesicle transition was determined by DLS and epifluorescence microscopy (sodachelins C and D and halochelins D. E. and F). Understanding the micelle-to-vesicle transition of selected halochelins could prove to be relevant for physiological aspects of iron uptake and future applications such as drug delivery systems or other biotechnological applications.

\section{Experimental section}

Bacterial strain growth and siderophore production and purification

To produce and harvest amphiphilic siderophores (halochelins and sodachelins). Halomonas sp. SL01 and SL.28 were grown in Soap Lake Media at $5 \%(w / v) \mathrm{NaCl}$ and room temperature. Cell growth and amphiphilic siderophore concentration were determined using optical density and the chrome azurol S assay. respectively. The chrome azurol S assay was used as described elsewhere. ${ }^{16}$ When maximum siderophore concentration was reached, siderophores were extracted from media supernatant (previously centrifuged and filtered) using C18 Varian cartridge columns and eluted with methanol and water mobile phases. Extracts were concentrated by lyoph- 
ilization or in vacuo evaporation $\left(40{ }^{\circ} \mathrm{C}, 4-6 \mathrm{~h}\right)$. Siderophore purification by HPLC was achieved with water (A) - acetonitrile (B) mobile phases ( $10 \%-70 \%$ gradient of B) in a C4 reverse column. Purified siderophore-containing fractions were pooled and lyophilized for further iron-mediated vesicle self-assembly.

\section{Siderophore-iron solution preparation}

First, purified, lyophilized siderophores were dissolved in 1-2 mL of ultrapure water. To check that chrome azurol S assay absorbance values were above 0.100 , corresponding dilutions were made $(1 / 5$. $1 / 10,1 / 25,1 / 50$, and 1/100) and chrome azurol S assays were performed. The optimal siderophore concentration to achieve was $>200 \mu \mathrm{mol} / \mathrm{L}$. which ensured that siderophores were above their cmc.

Second, iron solutions were prepared from $\mathrm{FeCl}_{3} \cdot 6 \mathrm{H}_{2} \mathrm{O}$ (Fisher) to yield different molar equivalents, $0.5 .1 .0 .1 .5,2.0,3.0$, and 4.0 equiv. of $\mathrm{Fe}^{3+}$, and then mixed with the siderophore solution. The iron solutions were filtered through a $0.22 \mu \mathrm{m}$ PES filter. Iron solutions $(50 \mu \mathrm{L})$ were added to an equal volume of siderophore solution and mixed. A volume of $80 \mu \mathrm{L}$ was discharged into a disposable Uvette cuvette (Eppendorf). which was sealed and used in the DLS analysis. Samples were protected from direct sunlight or UV light exposure to avoid photolysis (previously reported in other amphiphilic siderophores). ${ }^{17}$

\section{Particle size analysis by DLS}

A 90Plus Brookhaven zeta sizer was used to detect the transition from micelles to vesicles. Samples were tapped a few times to ensure resuspension of particles, placed in the cuvette chamber. and analyzed at $90^{\circ}$ angle from the detector. The measuring time was set to $5 \mathrm{~min}$ at $25^{\circ} \mathrm{C}$ and all samples were done in triplicate. Mean diameter and particle size distribution (by intensity scattering) were recorded to describe the whole suspended population.

\section{Siderophore-iron solution staining}

Epifluorescence microscopy was employed to provide visual confirmation of vesicle formation. Different lipophilic dyes are shown to successfully stain vesicles of $C$. neoformans. ${ }^{11}$ Among those dyes, the best performer in dyeing the vesicles is DiI $\left(1,1^{\prime}\right.$-dioctadecyl$3,3,3^{\prime}, 3^{\prime}$-tetramethylindocarbocyanine perchlorate: Vibrant DiI cell labeling solution) from Molecular Probes @Life Technologies ${ }^{\mathrm{TM}}$. In brief, $1 \mu \mathrm{L}$ of DiI was added to $100 \mu \mathrm{L}$ of siderophore and iron (0. 1.0. and 4.0 equiv. of $\mathrm{Fe}^{3+}$ ) solution. Ferric iron controls from $\mathrm{FeCl}_{3}$ were prepared at the corresponding equivalents: 1 or 4 equiv. of $\mathrm{Fe}^{3+}$. The mixtures were then incubated for $20 \mathrm{~min}$ at $37^{\circ} \mathrm{C}$ and then centrifugation was applied at $2100 \times \mathrm{g}$ for $5 \mathrm{~min}$ to initiate the washing steps. Accumulation of stained vesicles was visually observed at the bottom of the microcentrifuge tubes and the supernatant was removed carefully. Vesicles were resuspended in $100 \mu \mathrm{L}$ of nanopure water at $37^{\circ} \mathrm{C}$ and centrifuged. The wash step was repeated two more times to ensure removal of nonabsorbed dye by vesicles or micelles. A recovery period of $10 \mathrm{~min}$ followed to ensure dye delivery to the vesicle membrane or micelle core.

\section{Epifluorescence microscopy by cryoembedding and cryosectioning}

After staining with DiI, samples were cryoembedded as follows: a layer of Tissue-Tek@ OCT compound was added to a cryomold. topped with $80 \mu \mathrm{L}$ of previously stained siderophore-iron solution, covered with a second layer of OCT, and allowed to freeze on dry ice. Samples were cryosectioned in $5 \mu \mathrm{m}$ slabs in a Leica CM 1850 cryostat and placed on Fisherbrand@ Superfrost@ Plus glass slides. Images were taken on dry mounts with a Nikon Eclipse E800 microscope equipped with a Photometrics@ CoolSNAP MYO camera. Objectives used were a 10x Nikon Plan Apo dry WD 4.0. 20x Nikon Plan Apo dry WD 1.0, and a 60x Nikon Plan Apo dry WD 0.15 . Fluorescence of the fluorophore dye was achieved by using a PhotoFluor@ LM 7589 North UV lamp for excitation and a TRITC
Table 1. Mean diameters at different ferric iron equivalents for selected Halomonas sp. SLO1 halochelins (dynamic light scattering).

\begin{tabular}{llrr}
\hline Halochelin & $\begin{array}{l}\text { Equivalents } \\
\text { of Fe }\end{array}$ & $\begin{array}{l}\text { Mean } \\
\text { diameter }(\mathrm{nm})\end{array}$ & $\begin{array}{l}\text { SD } \\
\text { (nm) }\end{array}$ \\
\hline B & 0 & 1 & 0 \\
& 1 & 800 & 600 \\
C & 4 & 300 & 400 \\
& 0 & 8 & 2 \\
& 1 & 900 & 600 \\
D & 4 & 700 & 600 \\
& 0 & 1 & 0 \\
& 1 & 400 & 600 \\
E & 4 & 400 & 400 \\
& 0 & 1 & 0 \\
& 1 & 100 & 100 \\
F & 4 & 400 & 300 \\
& 0 & 6 & 1 \\
& 1 & 600 & 300 \\
& 4 & 800 & 500 \\
\hline
\end{tabular}

filter for absorption (549 $\mathrm{nm}$ ) and emission (565 nm) maxima. Image preparation and analysis (particle size count) was performed using MetaMorph@ software. Statistical analysis of particle size data was done with Minitab 16 and 17@.

\section{Results}

Particle size analysis by DLS: halochelins

Analyzed halochelins differ in their chemical structures. Halochelins B. C, and E are part of the first suite of amphiphilic siderophores produced by Halomonas SLO1. The head group is composed of the following amino acid sequence ( $\mathrm{N}$ - to $\mathrm{C}$-terminus): Phe-ThrCys-Arg-Gln-(Thr- $\beta$-OH-asp)-Ser-(D-N-OH-Orn). Halochelins B. C, and E fatty acyl moieties are C10:0, C12:0 3OH, and C12:0, respectively. Halochelins D and F belong to the second suite of amphiphilic siderophores produced and contrast in amino acid head group composition: Pro-Arg-Ser-(Thr- $\beta$-OH-asp)-Thr-Ser-(D-N-OH-Orn). Fatty acyl

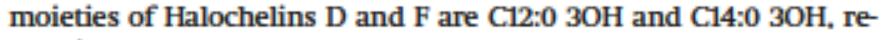
spectively.

DLS was used to describe the micelle-to-vesicle transition by changes in the mean hydrodynamic diameter of the resulting particles. The results output of the instrument generally appears as intensity distributions but volume and number distributions can also be selected. Intensity distributions were emphasized on larger particles but still provided a thorough understanding of the studied amphiphilic siderophores. Halochelin siderophores from Halomonas sp. SL01 and sodachelin siderophores from Halomonas SL28 were analyzed. The ability of amphiphilic siderophores to form vesicles in their ferri form (meaning that they are chelating ferric iron) has been shown in previous studies. In these studies, as the amount of coordinated iron, measured in iron molar equivalence, increases, micelle-to-vesicle transition occurs and the mean diameter of the resulting vesicle size increases. ${ }^{6,8}$ Halochelin $\mathrm{E}$. from the first family of siderophores, and halochelin $\mathrm{F}$ from the second family (Figs. 1A and 1B, respectively) showed similar patterns. In the absence of iron for both halochelins, the mean diameter was $1 \pm 0$ and $6 \pm 1 \mathrm{~nm}$ (Table 1). respectively. which is at the limit of detection of the instrument. When 1 equiv. of $\mathrm{Fe}^{3+}$ was added to solutions of halochelins $\mathrm{E}$ and $\mathrm{F}$, the diameter increased to $100 \pm 100$ and $600 \pm 300 \mathrm{~nm}$. respectively. At the higher 4 equiv. of $\mathrm{Fe}^{3+}$, the mean diameter increased for both halochelins to $400 \pm$ 300 and $800 \pm 500 \mathrm{~nm}$, respectively. The large standard deviations obtained were due to an increase in polydispersity of the system and probably to particle aggregation, causing high size variability. Note that halochelin $\mathrm{F}$ has a consistently larger mean diameter 
Fig. 2. Particle size distribution for halochelin E at (A) 0. (B) 1, and (C) 4 equiv. of $\mathrm{Fe}^{3+}$. Means and standard deviations are presented for each treatment; $N$ stands for the treatment population size.

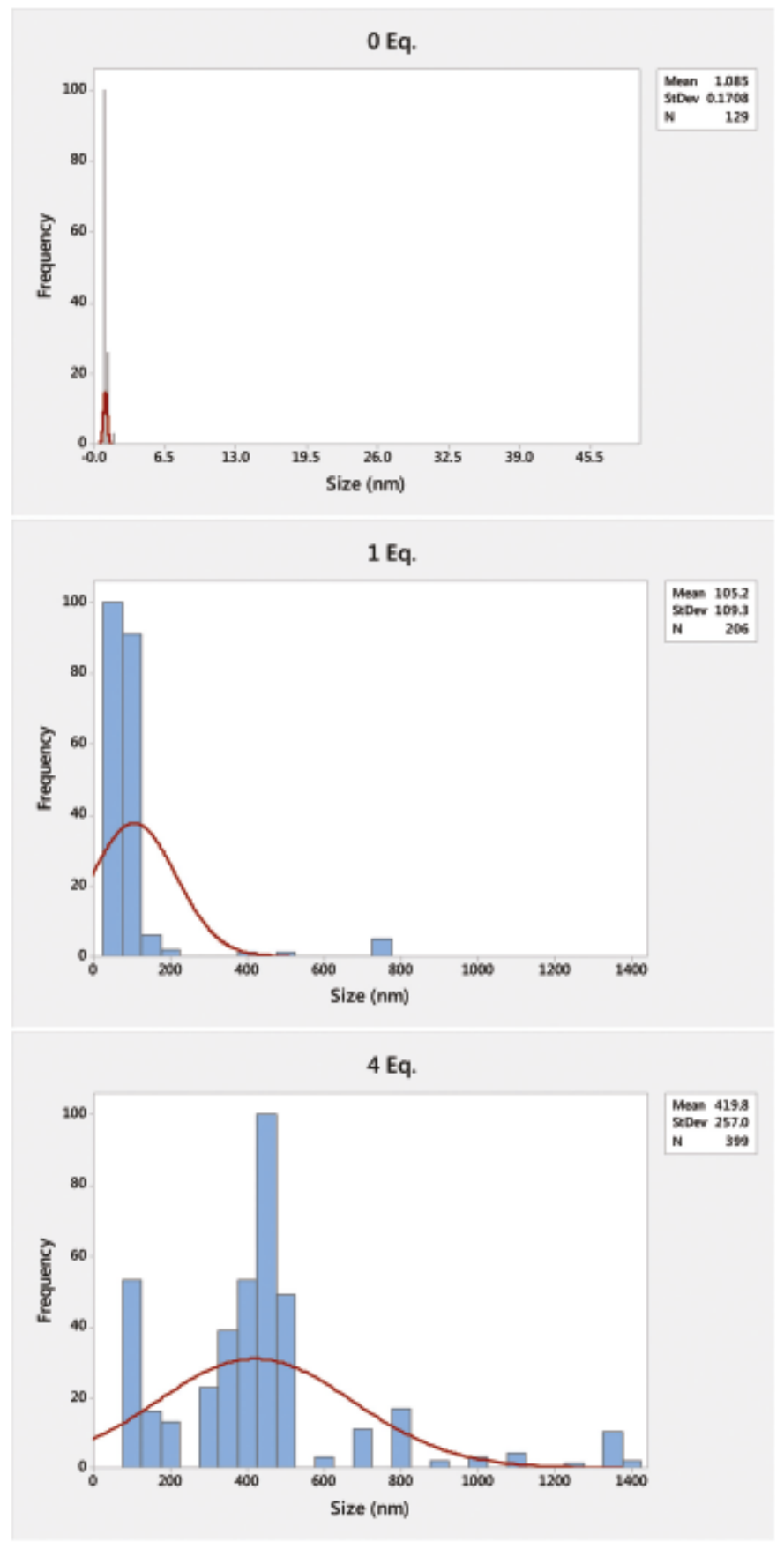

than halochelin E. This may be due to the longer fatty acid tail in the former (C14 versus C12).

Particle size distribution analysis was done for halochelin E. At 4 equiv. of $\mathrm{Fe}^{3+}$, there was greater distribution of vesicle sizes compared to the other treatments (Fig. 2). Four different population sizes can be observed at the 4 equiv. of $\mathrm{Fe}^{3+}$ treatment: (1) $<250 \mathrm{~nm}$, (2) between 250 and $500 \mathrm{~nm}$. (3) $600-1000 \mathrm{~nm}$, and (4) >1000 nm. A lower amount of iron resulted in a less polydisperse size distribution (two populations are detected). At no iron added, the distribution was monodisperse, suggesting more controlled micelle formation. There is a direct proportionality effect of $\mathrm{Fe}^{3+}$ equivalents and vesicle population numbers. This means that as ferric
Table 2. Mean diameters at different ferric iron equivalents for selected Halomonas sp. SL.28 sodachelins (dynamic light scattering).

\begin{tabular}{lllr}
\hline Sodachelin & $\begin{array}{l}\text { Equivalents } \\
\text { of } \mathrm{Fe}^{3+}\end{array}$ & $\begin{array}{l}\text { Mean } \\
\text { diameter }(\mathrm{nm})\end{array}$ & $\begin{array}{l}\text { SD } \\
(\mathrm{nm})\end{array}$ \\
\hline C & 0 & 1 & 0 \\
& 1 & 700 & 600 \\
D & 4 & 600 & 600 \\
& 0 & 2 & 1 \\
& 1 & 300 & 300 \\
E & 4 & 300 & 300 \\
& 0 & Not detected & \\
F & 1 & 700 & 600 \\
& 4 & 400 & 400 \\
& 0 & Not detected & \\
& 1 & 400 & 200 \\
& 4 & 400 & 300 \\
\hline
\end{tabular}

iron concentration increases, the number of vesicle individuals also increases (note legend and statistics panels of Fig. 2).

However, for halochelin $\mathrm{F}$, the 1 equiv. of $\mathrm{Fe}^{3+}$ treatments showed higher vesicle population numbers than for 4 and 0 equiv. of $\mathrm{Fe}^{3+}$ (supplementary Fig. S1 (see Supplementary material section)). The particle size distribution shows a polydisperse population, even more so than with halochelin E. At 1 equiv. of $\mathrm{Fe}^{3+}$, three populations are distinguished: (1) 0-150 nm. (2) 600-1200 nm, and (3) >1500 nm. Similar distribution was found at 4 equiv. of $\mathrm{Fe}^{3+}$. At no iron added. the distribution was monodisperse as in halochelin E. Statistical analysis showed that ferric iron treatments were significantly different for both siderophores (different grouping of ferric iron equivalent treatment means as per the Tukey method).

Apparently not all amphiphilic siderophores followed the pattern of increasing vesicle mean diameter as iron was added. As an example, halochelins B and C presented micelle sizes of about $1 \pm$ 0 and $8 \pm 2 \mathrm{~nm}$, respectively. Resulting particle sizes detected at 1 equiv. of $\mathrm{Fe}^{3+}$ were larger than those at 4 equiv. of $\mathrm{Fe}^{3+}$. A summary in Table 1 shows that for halochelin $\mathrm{B}$, the 1 equiv. of $\mathrm{Fe}^{3+}$ solution mean diameter was at $800 \pm 600 \mathrm{~nm}$ and for 4 equiv. of $\mathrm{Fe}^{3+}$ was $300 \pm 400 \mathrm{~nm}$. However, analysis showed statistical differences between 1 and 4 equiv. $\mathrm{Fe}^{3+}$ and their respective controls (different grouping of treatments means as per the Tukey method). A different case was observed for halochelin $\mathrm{D}$ in which no statistical difference was observed (as per the Tukey method showing iron equivalent treatment means in the same group). This also is observed in Table 1 where the 1 and 4 equiv. of $\mathrm{Fe}^{3+}$ treatment mean diameters for halochelin D were not different from each other (400 \pm 600 and $400 \pm 400 \mathrm{~nm}$, respectively).

Particle size analysis by DLS: sodachelins

Particle size studies were also conducted for two representative sodachelins produced by the isolate Halomonas sp. SL28 (Table 2). Sodachelin D exhibited the behavior of micelle-to-vesicle transition that was reported in previous literature suggested by changes in the hydrodynamic diameter of the particles. At 0 equiv. of $\mathrm{Fe}^{3+}$. micelles with a mean diameter of $2 \pm 1 \mathrm{~nm}$ were measured. Upon the addition of 1 and 4 equiv. of $\mathrm{Fe}^{3+}$, the mean diameter increased to $300 \pm 300 \mathrm{~nm}$ in both treatments. Statistical analysis showed differences between the treatments and their respective controls. However, the particle size distribution, shown in Fig. 3, indicates a more polydisperse distribution for the 4 equiv. of $\mathrm{Fe}^{3+}$ than at 1 equiv. of $\mathrm{Fe}^{3+}$. The treatment of 4 equiv. of $\mathrm{Fe}^{3+}$ added showed two population sizes: (1) $<450 \mathrm{~nm}$ and (2) $>1000 \mathrm{~nm}$. At 1 equiv. of $\mathrm{Fe}^{3+}$, the population was more polydisperse, showing three population sizes: (1) 0-450 nm, (2) 575-1000 nm, and (3) 1700- $2000 \mathrm{~nm}$. When no $\mathrm{Fe}^{3+}$ was added, the population was monodisperse as in previous particle size analyses. Statistical analysis of this siderophore at different $\mathrm{Fe}^{3+}$ equivalent treatments showed that each 
Fig. 3. Particle size distribution for sodachelin D at (A) 0, (B) 1, and (C) 4 equiv. of $\mathrm{Fe}^{3+}$. Means and standard deviations are presented for each treatment; $N$ stands for the treatment population size.

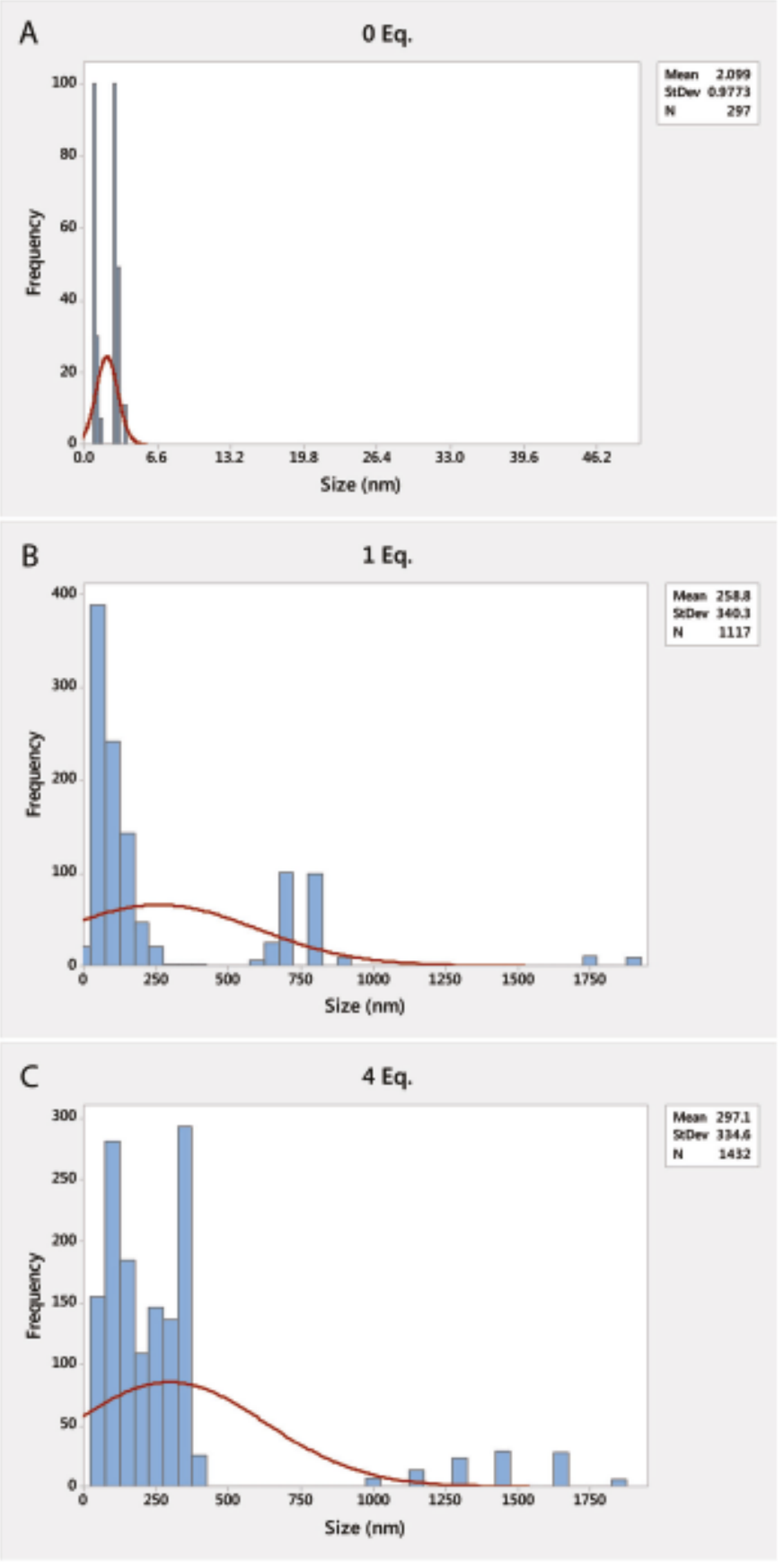

population was different from the others and the controls (means of treatments in different groups as per the Tukey method).

Sodachelin $\mathrm{F}$ followed a micelle-to-vesicle transition similar to that of sodachelin $\mathrm{D}$ because its 1 and 4 equiv. of $\mathrm{Fe}^{3+}$ treatments showed similar mean diameters (400 and $400 \pm 300 \mathrm{~nm}$, respectively). When $\mathrm{Fe}^{3+}$ was not added in the siderophore solution, no micelle formation was detected, but this may be due to the detection limit of the DLS instrument. No statistical differences were found (treatment means in the same group as per the Tukey method). Sodachelin $\mathrm{F}$ particle size distribution revealed size differences at 4 equiv. of $\mathrm{Fe}^{3+}$ added compared to 1 equiv. of $\mathrm{Fe}^{3+}$. At 4 equiv. of $\mathrm{Fe}^{3+}$, smallervesicles (<300 nm) were found (Fig. S2). As
Table 3. Epifluorescence mean diameters for selected halochelins (epifluorescence microscopy).

\begin{tabular}{llll}
\hline Halochelin & $\begin{array}{l}\text { Equivalents } \\
\text { of } \mathrm{Fe}^{3+}\end{array}$ & $\begin{array}{l}\text { Mean } \\
\text { diameter }(\mathrm{nm})\end{array}$ & $\begin{array}{l}\text { SD } \\
\text { (nm) }\end{array}$ \\
\hline D & 0 & 600 & 300 \\
& 1 & 700 & 500 \\
E & 4 & 900 & 700 \\
& 0 & 400 & 200 \\
& 1 & 400 & 300 \\
F & 4 & 600 & 300 \\
& 0 & 400 & 200 \\
& 1 & 500 & 200 \\
& 4 & 500 & 200 \\
\hline
\end{tabular}

more $\mathrm{Fe}^{3+}$ was added, the vesicle population size increased. For an example of control particle size analysis, refer to Fig. S3.

Table 2 shows that sodachelins $\mathrm{C}$ and $\mathrm{E}$ did not follow the typical micelle-to-vesicle transition compared to sodachelin D. Their 1 equiv. of $\mathrm{Fe}^{3+}$ treatment had higher mean diameters than at 4 equiv. of $\mathrm{Fe}^{3+}$ but high standard deviations suggested less size control in vesicle formation. No micelles were detected for sodachelins $\mathrm{E}$ and $\mathrm{F}$ at $\mathbf{0}$ equiv. of $\mathrm{Fe}^{+3}$. perhaps due to the limit of detection of the instrument ( $>1 \mathrm{~nm}$ ): thus, micelle formation in these sodachelins was not confirmed by DLS.

Epifluorescence microscopy for halochelins

To describe the micelle-to-vesicle transition in a qualitative way. epifluorescence microscopy was performed. A summary of vesicle and micelle sizes is presented in Table 3. Note the size difference at 0 equiv. of $\mathrm{Fe}^{3+}$ of these microscopic studies compared with values obtained with DLS. At this ferric iron treatment. the mean diameters were from 400 to $600 \mathrm{~nm}$, in contrast with no detection in some cases to $9 \mathrm{~nm}$ in size (using DLS). This size difference might be caused by agglomeration of vesicles during cryoembedding sample preparation. The size variability (by the standard deviation) was lower than with the DLS. Fluorescence was observed at no iron added for all halochelins. There was a proportional relationship between mean diameter size and $\mathrm{Fe}^{3+}$ added to halochelin D. but statistical analysis showed that halochelin $\mathrm{D}$ at 1 equiv. of $\mathrm{Fe}^{3+}$ was not significantly different from 0 equiv. of $\mathrm{Fe}^{3+}$ (both mean treatments grouped together as per the Tukey method). This suggests that the size change was not necessarily related to $\mathrm{Fe}^{3+}$ addition. In contrast, halochelins $\mathrm{E}$ and F did not show direct proportionality. and statistically. their sizes remained about the same (mean for each treatment grouped together as per the Tukey method, $p=0.364$ ).

Images showed an increase in fluorescence for halochelin D as more $\mathrm{Fe}^{3+}$ was added, suggesting micelle-to-vesicle formation (Fig. S4). Agglomeration appeared to occur in this system as an effect of the cryoembedding technique. At the 4 equiv. of $\mathrm{Fe}^{3+}$ treatment, there were some large amorphous stained particles and those were assumed to be ferric iron crystals. Staining could have occurred due to low solubility of ferric oxide crystals, conferring some hydrophobicity similar to the dye. Similar results were obtained for halochelins $\mathrm{E}$ and F(Fig. 4; Fig. S5). Fluorescence increased as ferric iron increased and agglomeration occurred at the highest $\mathrm{Fe}^{3+}$ equivalent treatment. In all cases, vesicle population size increased as $\mathrm{Fe}^{3+}$ increased in solution. Less fluorescence was observed at 0 equiv. of $\mathrm{Fe}^{3+}$ for both halochelins $\mathrm{E}$ and F and the particle sizes were smaller than that for halochelin D. In the absence of $\mathrm{Fe}^{3+}$. both treatments (for halochelins $\mathrm{E}$ and $\mathrm{F}$ ) were very similar in fluorescence. This was confirmed by the statistical analysis previously mentioned (grouped together as per the Tukey method). Representative $\mathrm{Fe}^{3+}$ control images can be found in Fig. S6.

Five images per treatment were analyzed to determine particle size distribution. In general, all had a normal distribution. In 
Fig. 4. Halochelin E epifluorescence images at different ferric iron equivalents: 0 (A). 1 (B). and 4 (C). Magnifications were 20x (Fig. 4B) and 60x (Figs. 4A and 4C). Scale bars are $10 \mu \mathrm{m}$ (Figs. 4A and 4C) and $25 \mu \mathrm{m}$ (Fig. 4B).

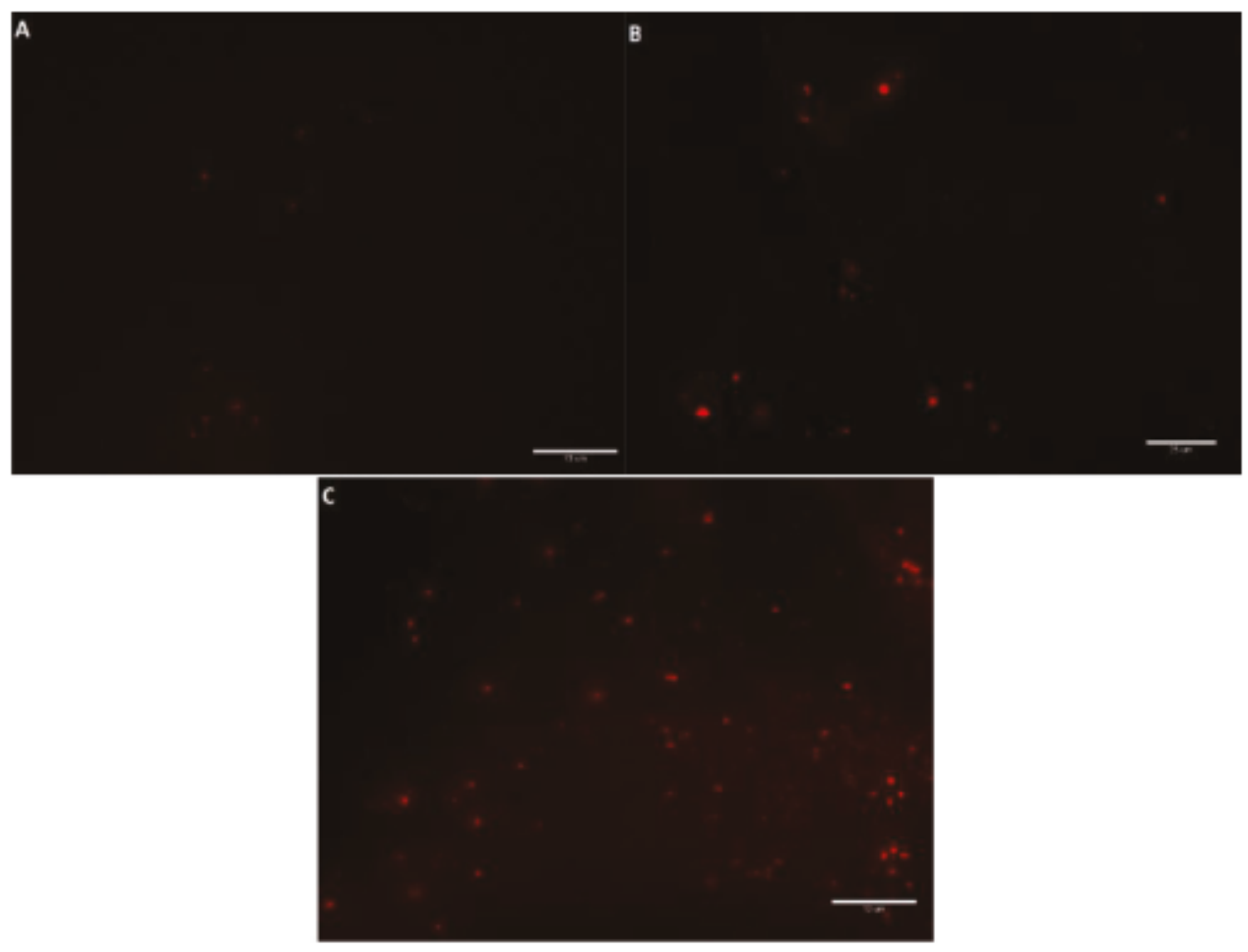

Fig. S6, halochelin D mean diameter increased but the vesicle population size decreased from 0 to 1 equiv. of $\mathrm{Fe}^{3+}$. That number increased again at 4 equiv. of $\mathrm{Fe}^{3+}$ added. The majority of the vesicle population was found in diameter sizes between 0 and $2000 \mathrm{~nm}$. At 4 equiv. of $\mathrm{Fe}^{3+}$. polydispersity was observed confirming what DLS results previously showed and suggesting micelleto-vesicle formation. Similar patterns were observed in halochelin $\mathrm{E}$ and $\mathrm{F}$ epifluorescence particle size distributions (Figs. S7 and S8). Fluorescence microscopy results correlated with micelle-to-vesicle transition due to an increase in vesicle population numbers. Particle size distributions for $\mathrm{Fe}^{3+}$ equivalent controls were performed and they can be found in the Figs. S9-S12.

\section{Epifluorescence microscopy for sodachelins}

Sodachelins C and D were also analyzed by microscopy using epifluorescence. In Table 4 , sodachelin $\mathrm{C}$ at 0 equiv. of $\mathrm{Fe}^{3+}$ showed a mean diameter of $500 \pm 200 \mathrm{~nm}$ but when ferric iron was added at the 1 equiv. of $\mathrm{Fe}^{3+}$ level, the diameter size decreased to $400 \pm$ $200 \mathrm{~nm}$. The addition of more iron (4 equiv. of $\mathrm{Fe}^{3+}$ ) created an increase of the mean diameter size to $500 \pm 400 \mathrm{~nm}$. In all treatments, the standard deviations were very high and statistical analysis demonstrated that only at 1 equiv. of $\mathrm{Fe}^{3+}$ was there a statistical significance in size (grouping different from 4 and 0 equiv. of $\mathrm{Fe}^{3+}$ treatments as per the Tukey method, $p=0.017$ ). Sodachelin D also showed no statistically significant difference among all of the treatments, suggesting a different micelle-tovesicle formation from other siderophores. The mean diameter pattern was similar to that of sodachelin $\mathrm{C}$, decreasing in size at 1 equiv. of $\mathrm{Fe}^{3+}$ and increasing when iron levels increased to 4 equiv. of $\mathrm{Fe}^{3+}$.

Images for sodachelin $\mathrm{C}$ showed little difference in fluorescence (Fig. 5) for all treatments. This suggests immediate vesicle selfassembly and perhaps a micelle-to-vesicle transition as in other amphiphilic siderophores. In contrast, sodachelin D epifluorescence at the 4 equiv. of $\mathrm{Fe}^{3+}$ treatment was different from that at 1 and 0 equiv. of $\mathrm{Fe}^{3+}$ (see Fig. S13). However, no statistically significant difference was found (all treatment means grouped together as per the Tukey method, $p=0.135$ ). It seems that at 0 equiv.
Table 4. Epifluorescence mean diameters for selected sodachelins (epifluorescence microscopy).

\begin{tabular}{llll}
\hline Sodachelin & $\begin{array}{l}\text { Equivalents } \\
\text { of Fe }\end{array}$ & $\begin{array}{l}\text { Mean } \\
\text { diameter }(\mathrm{nm})\end{array}$ & $\begin{array}{l}\text { SD } \\
(\mathrm{nm})\end{array}$ \\
\hline C & 0 & 500 & 200 \\
& 1 & 400 & 200 \\
D & 4 & 500 & 400 \\
& 0 & 700 & 600 \\
& 1 & 500 & 200 \\
& 4 & 600 & 400 \\
\hline
\end{tabular}

of $\mathrm{Fe}^{3+}$, there was micelle formation in comparison to 1 equiv. of $\mathrm{Fe}^{3+}$ (which has less particles visible). Representative control ( $\mathrm{Fe}^{3+}$ only) images for sodachelins are given in Fig. S14.

Images were analyzed for particle size distribution as was done for the halochelins in the previous section. Particle size distributions were obtained for each treatment and siderophore. In Fig. S15, sodachelin C presented larger sizes of particles via this method $(>1200 \mathrm{~nm})$ at 4 equiv. of $\mathrm{Fe}^{3+}$. This may suggest the formation of iron oxides in the siderophore-iron solution as happened for the halochelins at the same treatment. The mean diameter at 0 equiv. of $\mathrm{Fe}^{3+}$ was $500 \pm 200 \mathrm{~nm}$ and that contrasts with the DLS value of about $1 \mathrm{~nm}$. Micelle agglomeration may cause an increase of particle size, making them difficult to detect individually. Adding 1 equiv.of $\mathrm{Fe}^{3+}$ decreased the mean diameter $(400 \pm 200 \mathrm{~nm})$ and adding 4 equiv. of $\mathrm{Fe}^{3+}$ restored sizes to the no-iron treatment value $(500 \pm 400 \mathrm{~nm})$. Population polydispersity was found at higher $\mathrm{Fe}^{3+}$ equivalent treatment and not at the low-iron or no-iron ones. The population sizes did not change for other siderophores (like halochelin F). Statistical analysis by oneway ANOVA revealed a significant difference at the 1 equiv. of $\mathrm{Fe}^{3+}$ treatment (grouped different from 4 and 0 equiv. of $\mathrm{Fe}^{3+}$ treatments as per the Tukey method, $p=0.017)$. suggesting vesicle formation due to ferric iron addition. The experiment with sodachelin $D$ is a very particular one with results similar to halochelin D (Fig. S16). Higher 
Fig. 5. Sodachelin C epifluorescence images at different ferric iron equivalents: 0 (A). 1 (B), and 4 (C). Magnifications were $20 \times$ and scale bars are $25 \mu \mathrm{m}$.

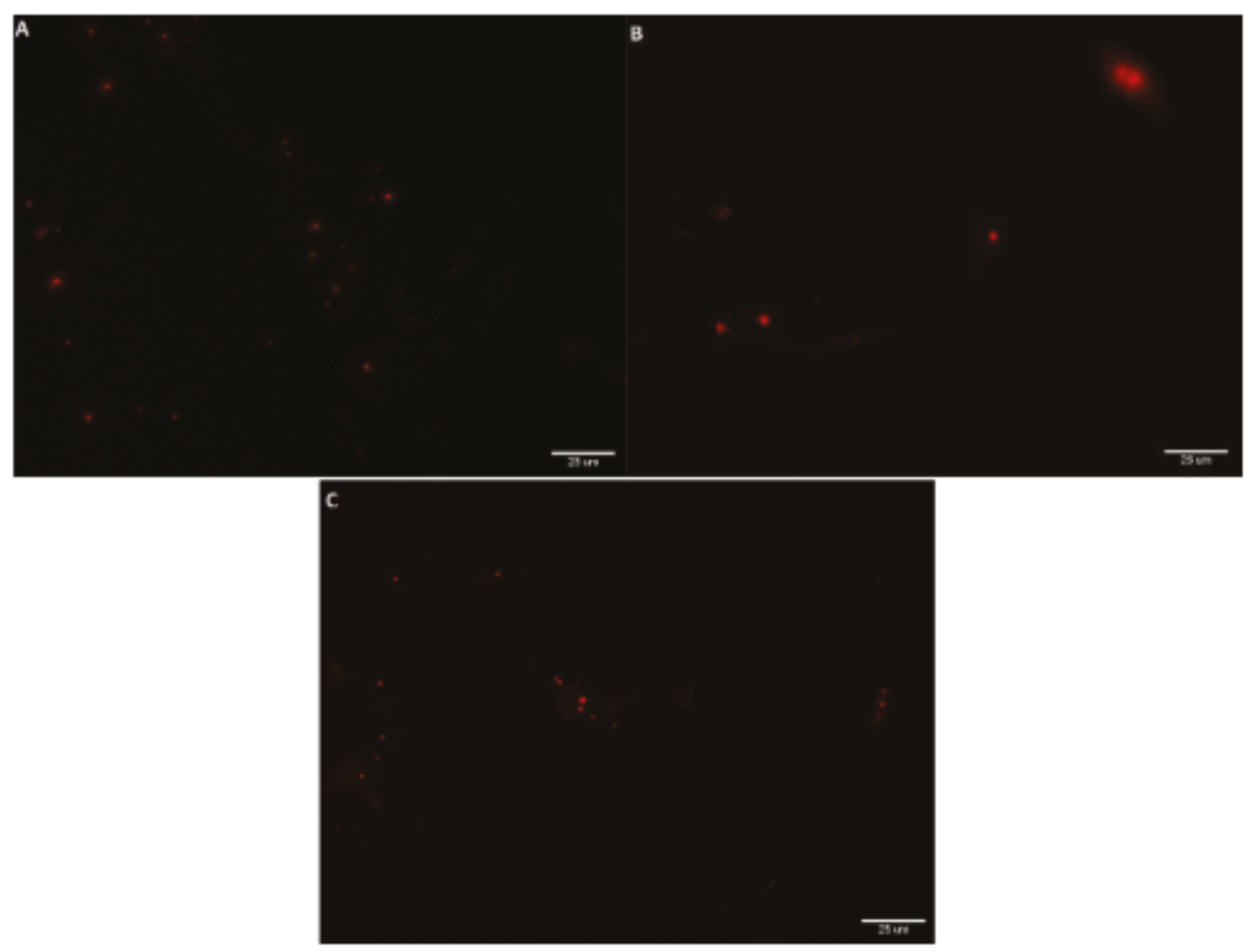

vesicle population size was expected at high-iron and low-iron equivalents, but experimental results did not confirm this. Oneway ANOVA statistical analysis revealed no difference among the treatments $(p=0.135)$. suggesting that vesicle formation may be due to other physical or chemical variables not accounted for in this experiment.

In summary. epifluorescence studies for halochelins and sodachelins in this report are not definitive, since the method lacks resolution to morphologically distinguish vesicles from micelles. Previous reports from other groups demonstrated micelle-to-vesicle transitions by utilizing TEM. ${ }^{6-8,18}$ In Martinez and co-workers (2000). cryoelectron micrographs showed vesicle formation when $\mathrm{Fe}^{3+}$ was added to marinobactin D. ${ }^{8}$ In Owen and coworkers (2007). marinobactin $\mathrm{E}-\mathrm{Fe}^{+3}$ particles were observed but the resolution was not sufficient to distinguish vesicle bilayers, thus making observed particles solid in appearance. ${ }^{7}$ With the information provided from these previous studies and having in mind the structural similarities of halochelins and sodachelins with marinobactins, we could deduct similar results if our study would include TEM.

\section{Discussion}

Previous research has presented vesicle and micelle formation of amphiphilic siderophores. ${ }^{\text {s,9,19 }}$ This physicochemical phenomenon is in part due to the molecule's amphiphilicity and is enhanced via metal chelation with zinc, cadmium, or ferric iron. ${ }^{6,7}$ Amphiphiles are in part hydrophobic and hydrophilic in their chemical structure and if they are over their cmc, micelles and vesicles will form. The results obtained during these experiments showed the metal dependency of micelle-to-vesicle formation of halochelins and sodachelins produced from Halomonas sp. SL01 and SL.28, respectively. All siderophores studied formed micelles when over their cmc in aqueous solution. It is believed that the micelle-to-vesicle transition occurs due to amphiphilic siderophore conformational change from the conical to cylindrical form when chelation of ferric iron takes place. ${ }^{20}$ Self-assembly and micelle-tovesicle transition of amphiphiles are affected by intermolecular and intramolecular forces, cmc, and thermodynamics. The intermolecular and intramolecular forces that have been described include steric, electrostatic (both van der Waals forces). hydrophobic, hydrophilic, and hydrogen bonding. In hydrocarbon chains, lateral pressure is developed from these forces, which straighten them and create chain pressure that pulls the amphiphile to the core (in the case of micelles) or center of the bilayer(forvesicles and membranes) and away from the aqueous phase. In contrast, steric and electrostatic interactions in coordination with hydration forces cause polar headgroup pressure, pulling the amphiphile towards the aqueous phase. An overall interfacial pressure develops between hydrophobic and hydrophilic regions of amphiphiles that generates forces that keeps the amphiphiles self-assembled in vesicles or micelles. The role that thermodynamics plays in self-assembly is that if the free energy per amphiphilic molecule is less than the disperse state, self-assembly would be favored. In amphiphilic siderophores, all of these forces in combination with $\mathrm{cmc}$ and excess $\mathrm{Fe}^{3+}$ produce a decrease in surface area of the head group by further carboxylate-mediated chelation changing the molecular conformation from conical to cylindrical.

Coordination chemistry studies have been performed on several model siderophores but no amphiphilic siderophores. Most $\mathrm{Fe}^{3+} \mathrm{co}-$ ordination complexes are formed by six oxygen atoms. Since the chemical composition of halochelins (which do not have the three usual donor groups) is different from that of sodachelins (which possess donor groups). we investigated in the literature the coordination potential for other atoms involved in our halochelins (nitrogen and sulfur). Methanobactin is a siderophore produced by the methane-oxydizing bacterium Methylosinus trichosporium OB3b. ${ }^{21}$ Methanobactin is composed of several amino acids and in that report, researchers developed and investigated the coordination crystal with copper. Researchers discovered that two sulfur atoms were involved in the coordination complex. Another research group investigated the coordination complex of yersiniabactin- $\mathrm{Fe}^{3+} .{ }^{22}$ Researchers were able to determine the atoms involved in the coordination complex to be nitrogen (one secondary amine and two secondary 
ketimine) and oxygen. Another report studied amychelin coordination chemistry with the ferric iron. ${ }^{23}$ Amychelin resembles amphiphilic siderophore structure but lacks the fatty acyl moiety in the $\mathrm{N}$-termini. In that study, a nitrogen (secondary ketimine) and five oxygen atoms were coordinating with the ferric iron. Halochelins B, $\mathrm{C}$, and $\mathrm{E}$ contain glutamine, arginine, and cysteine residues in the head group (Fig. 1) containing potential coordination atoms (nitrogen and sulfur) in addition to oxygen atoms. Halochelins D and F may use the arginine nitrogens (primary and secondary amines) or donor groups could come from either serine or threonine (both donating oxygen atoms to the complex). Future coordination chemistry studies should be done on halochelins and sodachelins to confirm the correct atom participation in these ferric iron-amphiphilic siderophore complexes.

DLS was used to describe the formation of vesicles upon iron chelation in reference to particle size distributions measured. Ferric addition and its subsequent chelation mediated micelle and vesicle formation in a concentration-dependent fashion. As the number of iron equivalents increased, the number of vesicles formed and their diameter size increased. Small micelles were measured for halochelins D, E, and F (1-6 nm) and at 1 or 4 equiv. of ferric iron, larger diametervesicles were observed. It is important to note that the molecule structure may play a role in the different sizes that were obtained by DLS. Halochelin F presented the larger diameter size $(800 \mathrm{~nm})$ contrasting with medium-sized diameters of halochelins D and $\mathrm{E}$ (both at $400 \mathrm{~nm}$ ). This may be due to halochelin F having a longer fatty acid moiety (C14:0) versus a C12:0 for both falochelin D and $\mathrm{E}$ fatty acid moieties (Fig. 1). In contrast, halochelin Bwas the siderophore with a smaller vesicle diameter size at 4 equiv. of $\mathrm{Fe}^{3+}$. This may be due to its shorter fatty acid moiety (C10 compared to the remaining halochelins ( $\mathrm{C} 12$ or $\mathrm{C14}$ ).

For the sodachelins, the structure of the molecule may be playing a similar role as for the halochelins. Both sodachelins $\mathrm{E}$ and $\mathrm{F}$ had larger mean diameters and this may be due to their longer C14 fatty acid moieties. Also, the double bond in the fatty acid may play a role in vesicle size because sodachelin $\mathrm{C}(\mathrm{C12}: 1 \omega 7 \mathrm{c})$ has a larger diameter than sodachelin D (C12:0). The hydroxyl (-OH) group on the fatty acid may also play a role in vesicle size due to repulsive interactions of the fatty acid moieties. Using this example, we can find halochelin $\mathrm{E}$ (with no- $\mathrm{OH}$ group at its fatty acid) with a smaller mean diameter size compared to halochelin C (with a-OH group on the third carbon position of its fatty acid). Even across families (halochelin E versus halochelin D or F), the group seems to be relevant. Size differences were not reported for vesicles formed by marinobactin siderophores, which had different fatty acid lengths. ${ }^{7}$

There might be some reasons for the large size particles found in microscopic studies of no-iron treatments. Micelles from synthetic amphiphilic siderophore-like ligands have been shown to agglomerate $^{10}$ and this might be the reason for the results observed here. Also, polydispersity of diameter size was found to be more common at high ferric iron equivalents for the amphiphilic siderophores studied. This phenomenon was found in a report by Owen and co-workers when 3 equiv. of $\mathrm{Zn}^{2+}$ was added to a ferric iron - marinobactin E complex. ${ }^{7}$ The group confirmed via cryoTEM and SANS that the vesicles were multilamellar in nature, something that was not observable in this study with the fluorescence technique. The variability in mean diameter between samples has also been described in previous research. ${ }^{6,7}$ Future studies for the amphiphiles analyzed here should include cryo-TEM and SANS to confirm what DIS and epifluorescence microscopy revealed.

The significance or importance of micelle or vesicle formation in amphiphilic siderophores could rest on maintaining the integrity of the molecule avoiding denaturation. Protection of decapeptides was described previously. ${ }^{19}$ The decapeptide attached to two C14 fatty acids was developed and subjected to proteolysis studies by trypsin. The lipopeptide self-assembled in tubular or helical forms and when trypsin was added, no hydrolysis occurred. Solu- bilization of the lipopeptide with detergent caused micelle formation and easy access of trypsin to the head group and subsequent hydrolysis. Hydrolysis has been reported, specifically fatty acid hydrolysis from the polar head group. when ferric iron is chelated in the presence of natural sunlight in a phenomenon called photoreactivity. ${ }^{24,25,26}$ The research studied amphiphilic siderophores (aquachelins) produced by Halomonas aquamarina DS40M3. The photoproduct was composed of ferrous iron $\left(\mathrm{Fe}^{2+}\right)$ and the cleaved fatty acid and head group. The head group lost its $\beta$-OH-asp moiety and this caused less ferric iron affinity by a decrease of the conditional stability constant. It is very important to note that ironaquachelin complexes were not over their cmc and thus, future studies of halochelin and sodachelin micelle-to-vesicle formation may investigate the possible protection from photoreactivity of these physical structures. It is important to note here that our experiments were protected from direct sunlight or UV light to avoid photolysis and misinterpretation of experimental results.

Studying micelle-to-vesicle formation will help us understand how these structural conformations could be applied in other fields of science or biomedicine. Previous applied research on siderophore ligands and conjugates has been reported $27,28,29$ The science behind these studies relies on conjugating an antibiotic or antimicrobial to a ferri-siderophore complex that is employed as a "Trojan horse" delivery system. The antibiotic-ligand-siderophore complex is internalized by the pathogenic bacteria's iron uptake transport system. Release of the antibiotic occurs as the complex is recycled by the cell metabolism. The disadvantage is that the complex is not protected from enzymes that may degrade the antimicrobial or the complex. In contrast, utilizing vesicles or micelles could hinder this degradation effect. Lipid-based (liposomes) delivery systems have been studied as therapeutics for bacterial infections ${ }^{30,31}$ or tumors. ${ }^{32,33} \mathrm{He}$ and coworkers (2013) studied the effects of polymyxin B liposomes on Pseudomonas aeruginosas mice lung infection models. ${ }^{30}$ Bacterial burden was reduced and prolonged survival of animals was observed. In tumor biology research, in vitro and in vivo experiments were performed utilizing chlorotoxin-loaded liposomes as therapeutic agents for breast cancer. ${ }^{33}$ Toxicity assays revealed drug-loaded liposome binding to tumors. BALB/c mice were treated and size reduction of the metastatic tumor was observed. Iron-mediated vesicle formation could also lead to the utilization of these structures as magnetic-responsive biomaterials. Iron response to magnetic fields makes the element a prime candidate for medical and biomedical imaging applications. ${ }^{34,35}$ Further studies on amphiphilic properties of halochelin and sodachelin should be done to determine the potential as drug carriers (antibiotics, antimycotics, and antitumorals) and imaging agents. The studies could look at the vesicle incorporation of the drug and describe the system at pharmacokinetical and pharmacological levels. Vesicle-microbe and vesicle-tumor interactions could be studied to help determine how the internalization process occurs.

\section{Conclusions}

Micelle-tovesicle transitions of selected halochelins and sodachelins were described and found to be ferric iron dependent. DLS studies revealed transitions from micelle to vesicles and provided information on size distribution of halochelins and sodachelins. Size distributions were polydisperse in nature, especially at higher ferric iron equivalents, suggesting potential aggregation of amphiphilic siderophores in solution. This was confirmed by epifluorescence microscopy studies in which vesicle aggregates were visible. Polydispersity patterns of vesicle populations ranged from small- to mid- to large-sized groups. Vesicle sizes are apparently directly correlated with the molecular structure of halochelins and sodachelins. Thus, amphiphilic siderophores with shorter fatty acid moieties (C12) have smaller vesicle diameters than those amphiphilic siderophores with longer (C14) fatty acid moieties. 
The utilization of epifluorescence microscopy helps describe the micelle-to-vesicle transition in a qualitative way. Little micelle orvesicle fluorescence was detected at lower ferric iron equivalents ( 0 or 1 equiv. of $\mathrm{Fe}^{3+}$ ) but an abundance of fluorescence was observed at higher iron equivalents ( 4 equiv. of $\mathrm{Fe}^{3+}$ ). This qualitative result correlated with previous quantitative DLS measurements. Polydispersity was observed to a lesser degree in microscopy experiments and this may be due to the fact that cryoembedding and cryosectioning were employed, causing close to normal distribution size populations. Standard deviations were higher in epifluorescence experiments versus DLS because of sample cryoembedding and cryosectioning as well. Performing cryosectioning creates cuts that may not be exactly throughout the center of the vesicle or micelle, therefore increasing or decreasing the particle mean diameter size. However, epifluorescence microscopy demonstrated that the micelle-to-vesicle transition was ferric iron dependent. More investigations should be done to optimize epifluorescence variables (amount of dye used and equilibration and incubation periods) in micelle-to-vesicle transition studies of amphiphilic siderophores.

\section{Supplementary material}

Supplementary material is available with the article through the journal Web site at http://nrcresearchpress.com/doi/suppl/ 10.1139/cjc-2015-0173.

\section{Acknowledgements}

Special thanks to Mrs. Ann Willis for technical expertise in purification techniques and laboratory equipment training and setup. Thanks also to Dr. Royce Wilkinson for assistance with the lyophilizer. Funding for the project was provided by National Science Foundation grant No. EEC-0927109.

\section{References}

(1) Puskin, J. S. J. Mambr. Biol. 1977, 35 (1), 39. doi:10.1007/bf01869939.

(2) Wolff-Boenisch, D.; Traina, S. J. Chem. Geol. 2007,242 (1-2), 278. doi:10.1016/ j.chemgeo.2007.03.019.

(3) Mullen, L.; Gong, C; Czerwinski, K.J. Radioanal Nud. Cham. 2007, 273 (3), 683. doi: $10.1007 / 510967-007-0931-5$.

(4) Moll, H.; Glorius, M.; Johnsson, A.; Schaefer, M.; Budzikiewicz, H.; Pedersen, K.; Bernhard, G. Radiochim. Acta 2010, 98 (9-11), 571. doi:10.1524] ract.2010.755.

(5) Harris, W.; Amin, S.; Kupper, F.; Green, D.; Carrano, C. J.Am. Chan. Soc. 2007. 129 (40), 12263. doi: 10.1021 /ja073788v.

(6) Owen, T.; Pynn, R.; Martinez, J:; Butler, A. Langmuir 2005, 21 (26), 12109. doi:10.1021/la0519352.

(7) Owen, T.; Pynn, R.; Hammouda, B.; Butler, A. Langmuir 2007, 23 (18), 9393. doi:10.1021/la700671p.
(8) Martinez, J.; Zhang. G.; Holt, P.; Jung. H.; Carrano, C.; Haygood, M.; Butler, A. Science 2000, 287 (5456), 1245. doi:10.1126/science.287.5456.1245.

(9) Owen, T.; Webb, S.; Butler, A. Langmuir 2008, 24 (9), 4999. doi:10.1021/ la703833v.

(10) Bednarova, L; Brandel, J.; d'Hardemare, A.; Bednar. J: Serratrice, G.; Pierre, J. Qhemistry 2008, 14 (12), 3680. doi: $10.1002 /$ chem.200701644.

(11) Nicola, A. M.; Frases, S.; Casadevall, A. Eukaryotic Cell 2009, 8 (9), 1373. doi: 10.1128/EC.00044-09.

(12) Bergeron, A.; Pucci, L.; Bezzi, P.; Regazzi, R. PLoS One, 2014, 9 (2): e87758. doi:10.1371/journal.pone.0087758.

(13) Crivellato, E.; Candussio, L.; Rosati, A. M.; Decorti, G.; Klugmann, F. B.; Mallardi, F. Histodıan. J. 1999, 31 (10), 635. doi:10.1023/A:1003893218761.

(14) Chemin, M.; Brun, P.-M.; Lecommandoux, S.; Sandre, O.; Le, Meins, J.-F. Soft Matter 2012, 8 (10), 2867. doi: $10.1039 / \mathrm{c} 2 \mathrm{sm} 07188 \mathrm{f}$.

(15) Limozin, L.; Barmann, M.; Sackmann, E. Eur. Phys. J. E Soft Matter Biol. Phys. 2003, 10 (4), 319. doi:10.1140/epje/i2002-10118-9.

(16) Schwyn, B.; Neilands, J. B. Anal. Biodiem. 1987, 160 (1). 47. doi:10.1016/00032697(87)90612-9.

(D) Martinez, J.; Butler, A. J. Inorg. Biochem. 2007, 101 (11-12), 1692. doi:10.1016/j. jinorgbio. 2007.07 .007 .

(18) Israelachvili, J. N.; Marcelja, S.; Horn, R. G. Q. Rev. Biophys. 1980, 13 (2), 121. doi: $10.1017 /$ S0033583500001645.

(19) Lee, K. C.; Carlson, P. A.; Goldstein, A. S.; Yager, P.; Gelb, M. H. Langmuir 1999, 15 (17), 5500. doi: $10.102 \mathrm{y} / \mathrm{la} 9900 \mathrm{7} 75$.

(20) Butler, A.; Theisen, R. M. Coord. Chem. Rev. 2010, 254 (3-4), 288. doi:10.1016/ j.ccr.2009.09.010.

(21) Kim, H.; Graham, D; DiSpirito, A.; Alterman, M.; Galeva, N.; Larive, C; Asunskis, D.; Sherwood, P. Science 2004, 305 (5690), 1612. doi:10.1126/ science. 1098322.

(22) Miller, M. C.; Parkin, S.; Fetherston, J. D.; Perry. R. D.; DeMoll, E. J. Inorg. Biodıam. 2006, 100 (9). 1495. doi:10.1016/j.jinorgbio.2006.04.007.

(23) Seyedsayamdost, M. R.; Traxler, M. F.; Zheng, S.-L.; Kolter, R.; Clandy.J.J.Am. Chem. Soc. 2011, 133 (30), 11434. doi:10.1021/ja203577e.

(24) Barbeau, K.; Rue, E. L.; Bruland, K. W.; Butler,A.Nature 2001, 413 (6854), 409. doi: $10.1038 / 35096545$.

(25) Barbeau, K.; Rue, E. L.; Trick, C. G.; Bruland, K. T.; Butler, A. Limnol. Oceanogr. 2003, 48 (3), 1069.

(26) Kupper, F. C; Carrano, C. J.; Kuhn, J.-U.; Butler, A. Inorg. Oham. 2006, 45 (15). 6028. doi:10.1021/100604967.

(27) Ghosh, A.; Miller, M. J. J. Org. Chem. 1993, 58 (27), 7652. doi:10.1021/ jo00079a007.

(28) Miller, M. J. Abstr. Pap. Am. Chem. Soc. 1995, 209, 353.

(29) Ghosh, A.; Ghosh, M.; Niu, C.; Malouin, F; Moellmann, U.; Miller, M. J. Ohan. Biol. 1996, 3 (12), 1011. doi:10.1016/51074-5521(96)90167-2.

(30) He, J.; Abdelraouf, K.; Ledesma, K. R.; Chow, D. S. L.; Tam, V. H. Int. J. Antimicrob. Agants 2013, 42 (6). 559. doi:10.1016/j.jjantimicag.2013.07.009.

(31) Alhariri, M.;Azghani,A.; Omri,A.Expert Opinion on Drug Delivery 2013, 10 (11). 1515. doi: $10.1517 / 17425247.2013 .822860$.

(32) Kontogiannopoulos, K. N.; Tsermentseli, S. K.; Assimopoulou, A. N.; Papageorgiou, V. P. J. Liposome Res. 2014, 24 (3). 230. doi:10.3109/08982104. 2014.891233.

(33) Qin, C.; He, B.; Dai, W.; Zhang. H.; Wang. X.; Wang. J.; Zhang, X.; Wang. G.; Yin, L;Zhang. Q. Md. Pharmacaut. 2014, 11 (10), 3233. doi:10.1024/mp4006917.

(34) Liu, Y.; Shi, M.; Xu, M.; Yang. H.; Wu, C. Expert Opinion on Drug Delivery 2012. 9 (10), 1197. doi:10.1517/7425247.2012.709845.

(35) Quarta, A.; Di Corato, R.; Manna, L.; Argentiere, S.; Cingolani, R.; Barbarella, G.; Pellegrino, T. J. Am. Cham. Soc. 2008, 130 (32), 10545. doi:10. $1024 j \mathrm{ja} 800102 \mathrm{v}$. 